- ACORN Australan college of | JOURNAL OF PERIOPERATIVE NURSING

\title{
Supporting paediatric patients: Parental presence in the anaesthetic journey
}

Follow this and additional works at: https://www.journal.acorn.org.au/jpn

Part of the Health Services Administration Commons, Health Services Research Commons, Perioperative, Operating Room and Surgical Nursing Commons, and the Surgery Commons

(c) (†)

This work is licensed under a Creative Commons Attribution 4.0 License.

\section{Recommended Citation}

Blake, Salina (2019) "Supporting paediatric patients: Parental presence in the anaesthetic journey," Journal of Perioperative Nursing: Vol. 32 : Iss. 4 , Article 4.

Available at: https://doi.org/10.26550/2209-1092.1070

https://www.journal.acorn.org.au/jpn/vol32/iss4/4

This Article is brought to you for free and open access by Journal of Perioperative Nursing. It has been accepted for inclusion in Journal of Perioperative Nursing by an authorized editor of Journal of Perioperative Nursing. 
Guest Editor

Paula Foran

PhD, MACN, FACORN

Author

Salina Blake

MN (Clinical Nursing \&

Teaching), GradDipPaed, RN

\title{
Supporting paediatric patients: Parental presence in the anaesthetic journey
}

\author{
Abstract \\ Objective \\ This discussion paper explores the use of parental presence during \\ induction of anaesthesia as a method of decreasing paediatric and parental \\ perioperative anxiety.
}

\section{Setting}

A perioperative department in an Australian public hospital.

\section{Subjects}

Paediatric patients and parents/guardians.

\section{Primary argument}

There is evidence to support the importance of parental presence in the anaesthetic setting; however, this varies between different health care facilities. This paper will argue that the presence of the parent during induction of anaesthesia will decrease the anxiety of the child. However, there has been little discussion about the pivotal role parents can play when participating in the anaesthetic process. Parents need to be given a clear orientation and specific instruction regarding their role during induction of anaesthesia to ensure that the child's anaesthesia is safe.

\section{Conclusion}

Parental presence during induction of anaesthetic of a child may be a controversial practice in some hospitals; however, evidence states that it can reduce anxiety for the child. The presence of the parent working alongside the anaesthetic team combined with insight and understanding provided by a preoperative visit can assist in reducing anxiety for the child and parent.

Keywords: anaesthesia, anxiety, child, parental presence, perioperative

\section{Introduction}

Perioperative anxiety can have a significant effect on paediatric patients. It is noted that 40 to 60 per cent of children having surgical procedures suffer high levels of anxiety ${ }^{1}$. Anaesthetic induction can be extremely stressful for children and it may have damaging effects on the child's physiological and mental health². There have been advances in the management of anxiety in paediatric anaesthesia. Clinicians have developed tools to measure anxiety such as the visual analogue Modified Yale Preoperative Anxiety Scale (m-YPAS) 3 . Other clinical practice developments to manage paediatric anaesthetic anxiety have been developed such as preoperative visits, parental presence, pharmacological interventions, audio and visual aids ${ }^{1,4}$, clown doctors ${ }^{5}$ and comic books ${ }^{6}$. Despite many of these initiatives, paediatric perioperative anxiety is still prevalent and can be a traumatic experience for both the child and the parent? 
Not all operating suites allow parents to be present for the anaesthetic induction or have preoperative visits for children. Of those that do, some children and parents are either transported to the anaesthetic room or directly into theatre for care without orientation to the new environment. For parental presence to be an effective practice in paediatric anaesthesia, parents will need support and instruction when in the induction area to understand the sequence of events and how they can best support their child ${ }^{8}$. Inclusion of parents during induction of anaesthesia is a practice that aligns with a family-centred model of care. Family-centred models of care encompass the concepts of parental participation in decision making, and partnership and collaboration between the health care team and parents?

This discussion paper will examine and discuss the cause and effect of preoperative paediatric anxiety. The benefits of parental presence to reduce anxiety during induction of anaesthesia in children will be analysed. Finally, considerations of the pivotal role parents can play when participating in the anaesthetic process will be presented with discussion about the collaboration between the health care team and the parents to reduce paediatric anxiety.

For the purposes of this paper, a child is defined as a person who is 19 years or younger, unless national law states this person to be an adult ${ }^{10}$. The term 'parent' will refer to the child's main support person but may also be a carer or guardian.

\section{Paediatric perioperative anxiety}

Erhaze et al. state that 50 to 75 per cent of children suffer perioperative anxiety ${ }^{11}$; therefore, gaining a comprehensive understanding of anxiety before and after surgery is required to determine specific causes for it. Perioperative anxiety can be caused by preconceived ideas, parental separation, lack of control, unfamiliar people and surroundings, and the lack of preparedness for surgery of the child and parent ${ }^{11}$. Stress and anxiety can have detrimental effects including reduced patient compliance, unsafe airway control, emergence delirium, increased post-operative pain and adverse post-operative behaviour changes $^{12}$.

Paediatric induction of anaesthesia can cause considerable anxiety for both the child and the parent? Induction may be administered by either inhalation or intravenous methods. Inhalation agents are delivered through a face mask connected to an anaesthetic breathing circuit which when applied covers the nose and mouth of the child. Most commonly the inhalational route is preferred given that children are normally afraid of needles ${ }^{13}$. During an inhalational induction the child may resist, try to flee, protest and cause themselves harm $^{13}$. Sevoflurane can also produce this type of stimulation stimulus ${ }^{14}$. Observing this behaviour can be distressing for the parent if they have not been orientated and prepared for this outcome of care.

\section{Effects of perioperative anxiety at the point of care and recovery}

Paediatric perioperative anxiety stimulates the sympathetic nervous system and the endocrine system causing increased heart rate, raised blood pressure and cardiac instability, and consequently arrhythmias ${ }^{15}$. Issues can continue post-operatively leading to waking up during the night, separation anxiety, temper tantrums, disobeying parents, bed wetting and withdrawal behaviour ${ }^{15}$. This regressive behaviour has been demonstrated to continue for up to a year post-operatively with separation anxiety and night waking being the most predominant issues $^{16}$. Paediatric anxiety can also delay wound healing as a result of the release of cortisol and catecholamines which cause changes to cellular transfer, proliferation, antibody production and cytokine secretion ${ }^{17}$.

Pharmacological interventions such as benzodiazepines can be used to alleviate anxiety in children, both for the first time a child undergoes anaesthesia and repeated surgery ${ }^{18}$. There is agreement that giving a premedication can ensure a smoother induction for some children and parents ${ }^{18}$. However, it is important to highlight that use of benzodiazepines can cause adverse effects such as paradoxical reactions, extended sedation in recovery and unpleasant behavioural changes ${ }^{19}$.

Erhaze et al. note that premedication in combination with parental presence may have a more beneficial impact on care than one method of care alone ${ }^{11}$. The greater goal may be the introduction of procedures that allow parental presence during the induction of anaesthesia and reduce the need to pre-medicate a child preoperatively.

\section{Discussion}

There are several areas where a child can be anaesthetised - the operating theatre, anaesthetic room, paediatric intensive care unit and remote areas such as radiology and oncology. Anxiety during anaesthesia can affect a child's physiological functioning ${ }^{20}$. Psychological changes are associated with each developmental age and the physical environment will have an impact on the management of the child's anxiety ${ }^{21}$. In addition, the experience of separation anxiety, coupled with parental apprehension of leaving their child in the care of strangers, can affect the child's 
personality, physical growth and their emotional development ${ }^{21}$.

\section{Parental presence}

The practice of parental presence during anaesthetic induction is commonplace in many hospitals while still controversial in others; however, the strong alignment of this with the family-centred model of care in children cannot be denied. Family-centred care is a gold standard level of care and is the practice of planning care around the whole family rather than the child as an individual22. A study by Sadeghi et al. states that parental presence reduces children's anxiety and improves the anaesthetic induction as well as increasing parental satisfaction ${ }^{2}$. Yousef et al. found that initially surgeons were reluctant to have parents present in the theatres as they believed it would add time to their surgical list ${ }^{23}$; however, after the implementation of a structured parental presence process they praised it as beneficial to the perioperative process. The parent's ability to assist the child with distraction assisted with a prompt anaesthetic induction ${ }^{13}$.

The Children's Hospital Network is viewed as a benchmark for paediatric patients in New South Wales ${ }^{24}$. The network states that the anaesthetist, in conjunction with parents and staff, have the final decision on the presence of parents during induction. Parental presence offers benefits to both the child and parents when planned and negotiated with the health care team and is an important aspect of holistic care ${ }^{25}$. When a defined process that is backed up by hospital policy and education has not been introduced, medical and nursing staff may find the presence of parents challenging ${ }^{26}$. Therefore, it is vital that all staff have received education about the parental presence procedures and processes.
A policy should signify when parental presence is not acceptable ${ }^{27}$.

Literature states defining age groups as important. Infants below eight months seldom benefit from parental presence during induction; similarly, these infants are at high risk for complications and parental presence may hinder the anaesthetic process ${ }^{28}$. Policies will give clinicians clear guidance as to perioperative anaesthetic expectations and children will benefit from this practice as they will receive consistent psychological care throughout their surgical pathway. Further age considerations are important for children between the ages of two to six years who are more likely to display anxiety at induction (see Table 1) ${ }^{24}$.

Aguilar Cordero et al. support the importance of parental presence as a method to reduce salivary cortisol as an indicator of physiological stress and anxiety ${ }^{29}$. Cortisol is secreted by the hypothalamus pituitary adrenal axis in reaction to stress ${ }^{29}$. Ozdogan et al. also found cortisol levels were reduced in children who had parents present during perioperative procedures, confirming that stress was lowered during these phases ${ }^{30}$. However, Rasti-Emad-Abadi et al. found that parental presence had no value in reducing paediatric anxiety when the education was given and the procedure attended on the same day $^{31}$. Ozdogan et al. noted that the implementation of a parental presence policy must be layered and a child and parent must be prepared for parental presence prior to the procedure ${ }^{30}$. Therefore, more time must be taken to prepare for parental presence to achieve the best health care outcome for the child.

Incorporating a preoperative visit prior to the procedure, giving the opportunity to familiarise the child and the parent with the environment and sequence of events for the procedure, may lead to a more successful outcome ${ }^{32}$. Parents would have adequate opportunities for questions and be able to make informed decisions about their child's care. This will create parental empowerment as they are involved in their child's care ${ }^{33}$. Meeting the team prior to the event will help reduce stranger anxiety for the child, build trust with clinicians and assist in maintaining healthy attachment to their parent ${ }^{33}$. The benefits of parental presence are clearly demonstrated in the literature, showing that parental presence during anaesthesia improves the experience of care for not only the patient and parent but also assists treating clinicians when the parent understands their role?

\section{Parental presence process one: Preoperative visit}

The unfamiliar surroundings of the hospital, a lack of preoperative preparation, painful procedures and fear of medical equipment can all have an impact on a child's perioperative anxiety ${ }^{34}$. The preoperative visit would de-escalate these fears in a non-threatening way by familiarising the child with the equipment. The introduction of a preoperative visit can assist parents and child with levels of anxiety ${ }^{35}$. Not all institutions facilitate preoperative visits to the operating room; however, this activity could be encouraged if it is evidenced and supported by leaders to be best practice. The specialist appointment would be a suitable time for the preoperative visit to be discussed ${ }^{36}$. Not all parents will take advantage of this; nonetheless, it should be made available.

The Australian and New Zealand College of Anaesthetists 'Guidelines on pre-anaesthesia consultation and patient preparation PSO7 ${ }^{\prime 37}$ note the importance of information and state that the pre-anaesthetic 
assessment should consider the developmental age of the child, the location and level of awareness of the surgical procedure of both parents and child. Anxiety can be reduced by establishing rapport and ensuring a good understanding of the anaesthetic process. A preoperative visit would be an advantageous time to carry out screening to assess parent's anxiety and create awareness about their level of coping mechanisms ${ }^{38}$. A child's coping behaviour is related to parental coping behaviour and parental distress can cause distress-related behaviours in the child ${ }^{38}$. While it is well known that parental distress can elevate anxiety in the child, parental anxiety and behaviour can be lessened when given exceptional preoperative preparation and information, with a reported 99 per cent of parents declaring that they felt more able to cope and were more prepared when they understood exactly what was to occur ${ }^{39}$. An additional point is to establish who the child generally seeks consolation from, as the parent who provides this may be favoured as the one who escorts the child to theatre rather than the one who feels it is their role, whatever anxiety they might be feeling themselves. Preoperative discussions with parents about strategies that console the child at home such as singing or reading their favourite book will also assist the process.

During the preoperative visit, the parent will don a gown and hat as they will on the surgical day. Handling equipment and education about it can lower anxiety levels, so the parent and child will have a demonstration of equipment to be used in a way that children will find comforting rather than frightening, such as explaining wearing the face mask in relation to what happens when you blow up a balloon or being a space traveller ${ }^{8}$.
Depending on the child, they may be able to be held by the parent for induction ${ }^{8}$. This informal visit and the role of the parent is vitally important and will benefit the child and parent as it familiarises them with the forthcoming scenarios and environment under the guide of the family-centred care model ${ }^{35}$.

\section{Parental presence process two: Environment}

Anaesthetic rooms are routinely used in the UK for induction of anaesthetic; however, this may only be as a result of tradition ${ }^{40}$. This is not routinely the case in Australia. The anaesthetic room can, however, provide a quiet and comfortable environment for children and parents. Moreover, using the anaesthetic room for induction of anaesthetic has been found to reduce the anxiety associated with seeing and hearing preparations for surgery, and also limits distractions and interruptions during induction of anaesthesia ${ }^{40}$ as well as limiting the number of staff present ${ }^{41}$. If the physical space is not adapted to suit children, they may experience it as boring and frightening 32 .

Literature regarding an anaesthetic room induction discusses concerns of safety risks during transfer to the operating theatre such as hypoxia, awareness during transfer and lack of monitoring ${ }^{42}$. The transfer time is minimal, being less than five minutes in most perioperative areas, and involves the movement of the anaesthetised patient to the operating theatre and transfer onto the surgical operating table. The anaesthetic circuit and monitoring can be connected on arrival in theatre. In addition, the risk of the patient being unmonitored during the transfer time can be alleviated with the use of a portable demountable brick monitor ${ }^{42}$.

In-theatre induction can cause anxiety because of the noise of preparation and the number of staff in theatre. There are also the issues of infection control which need to be taken into consideration, due to parents entering the theatre in gowns rather than full surgical attire and the use of an external ward bed. Therefore, a parent and child must be orientated to the environment prior to the event as this will support a positive parental presence ${ }^{36}$.

Parental presence process three: Different approaches to different age groups

The final consideration for parental presence is to understand that different processes for presenting information will be required for different age ranges of children. Parents will need to be aware of what is important to support their child in the anaesthetic environment while the child adapts using emotional self-regulation ${ }^{43}$. Infants and young children use facial expressions, gestures or rhythmic sounds to express themselves ${ }^{44}$. Between seven and nine months, infants begin to realise that an object exists even if it can no longer be seen. This is important for parents to know as they provide distractions for children during anaesthetic induction (see Table 1) ${ }^{45}$.

In the younger child, verbal interaction is vital. Direct questions that are simple and descriptive are helpful if the child is scared; they will not answer open-ended questions ${ }^{44,46}$. 'Gaze tracking', when the child follows the interaction of the anaesthetist and others, is an indication that the child's response is positive ${ }^{47}$ as it demonstrates the child is taking notice and is focused, since listener responses are naturally a shaking of the head and verbal responses are non-existent in preschoolaged children ${ }^{46}$. Older children and adolescents can be engaged when asked about their interests. It is imperative to establish trust with the 
Table 1: How the anaesthetic team can assist with anxiety of the child (adapted from Piaget's theory of cognitive development ${ }^{48}$ )

\begin{tabular}{|c|c|c|c|}
\hline Stage & Age range & Description of stage & $\begin{array}{l}\text { Possible strategy during induction of } \\
\text { anaesthesia }\end{array}$ \\
\hline Sensorimotor & Under 2 years & $\begin{array}{l}\text { Coordination of motor response with senses. Language } \\
\text { used for demands and classification. Throwing toys. } \\
\text { Separation anxiety and distressing inductions as a } \\
\text { result of not understanding the process. }\end{array}$ & Distraction using toys and stories. \\
\hline Preoperational & 2 to 7 years & $\begin{array}{l}\text { Use of proper composition and grammar. Imagination } \\
\text { and intuition are strong. Conversation developed. }\end{array}$ & $\begin{array}{l}\text { Reassure with simple explanations. Talk to child at } \\
\text { eye level. }\end{array}$ \\
\hline Concrete operational & 7 to 11 years & $\begin{array}{l}\text { Concrete concepts attached to situations. Space, time } \\
\text { and quantity are established; however, not individually. }\end{array}$ & $\begin{array}{l}\text { Explain and allow participation to help child feel in } \\
\text { control e.g. child holding facemask, playing games, } \\
\text { watching videos. }\end{array}$ \\
\hline Formal operations & $\begin{array}{l}12 \text { years to } \\
\text { adolescence }\end{array}$ & $\begin{array}{l}\text { Uses abstract, logical and formal thinking. } \\
\text { Planning becomes possible. }\end{array}$ & Acknowledge and allow control in plan. \\
\hline
\end{tabular}

child and the child must be engaged. Table 1 explains the different development stages, presenting the characteristics of the age groups and how the anaesthetic team can assist with anxiety of the child.

\section{Recommendations}

Encouraging a preoperative visit before the day of surgery or procedure is recommended. Orienting both the child and parents to the surgery or procedure before the day and using parents as a source of comfort would assist in reduction of paediatric perioperative anxiety. Furthermore, the parents would be familiar with the script and routine of the anaesthetic induction, enhancing their role, and allowing them to be an integral part of the anaesthetic process. Development of structured policy and procedure for parental presence needs to be developed by health care leaders and further studies of the implementation of parental presence processes are required in this area to validate the effect parental presence has on paediatric anaesthetic anxiety.

\section{Conclusion}

Parental presence during the induction of anaesthetic of a paediatric patient is sometimes a contentious subject; however, literature states that it can reduce anxiety for the child. It has also been found that children have less post-operative pain and behavioural issues if anxiety levels are lowered thus leading to reduced physiological damage. The structured preoperative visit can introduce information and increase understanding of both parent and child which will assist with reduced anxiety for both and ensure the parent positively assists in the anaesthetic process.

\section{Acknowledgment}

This work was submitted to the University of Tasmania as a partial requirement in master's degree subject CNA803. The author would like to acknowledge Dr Paula Foran, unit co-ordinator and tutor, for her encouragement and direction in writing this discussion piece.

\section{References}

1. Liguori S, Stacchini M, Ciofi D, Olivini N, Bisogni S, Festini F. Effectiveness of an app for reducing preoperative anxiety in children: A randomized clinical trial. JAMA Pediatr 2016;170(8):e160533.

2. Sadeghi A, Khaleghnejad Tabari A, Mahdavi A, Salarian S, Razavi S. Impact of parental presence during induction of anesthesia on anxiety level among pediatric patients and their parents: a randomized clinical trial. Neuropsychiatr Dis Treat 2017;12:3237-3241.
3. Berghmans J, Marten M, Poley J, Van der Ende J, Weber $F$, Van de Velde $M$ et al. A visual analog scale to assess anxiety in children during anaesthesia induction (VAS-I): Results supporting its validity in a sample of day care surgery patients. Pediatric Anesth 2017;27(9):955-996.

4. Kim H, Jung SM, Yu H, Park SJ. Video distraction and parental presence for the management of preoperative anxiety and post-operative behavioral disturbance in children: A randomized controlled trial. Anaesth Analg 2015;121(3):778-784.

5. Zhang Y, Yang Y, Lau WY, Garg S, Lao J. Effectiveness of pre-operative clown intervention on psychological distress: A systematic review and meta-analysis. J Paediatr Child Health 2017;53(3):237-245.

6. Kassai B, Rabilloud M, Dantony E, Grousson S, Revol O, Malik S et al. Introduction of a paediatric anaesthesia comic information leaflet reduced preoperative anxiety in children. Br J Anaesth 2016;117(1):95-102.

7. Luehmann NC, Staubach ME, Akay B, Collier PJ, Han RE, Riggs TW et al. Benefits of a family-centered approach to pediatric induction of anesthesia. J Pediatr Surg 2019;54(1):189-193.

8. Bailey KM, Bird SJ, McGrath PJ, Chorney JE. Preparing parents to be present for their child's anaesthesia induction: A randomized controlled trial. Anesth Analg 2015;121(4):1001-1010.

9. National Safety and Quality Health Service (NSQHS). Care ACoSaQiH. National Safety and Quality Health Service Standard 2: Partnering with Consumers 2017. Sydney; NSQHS: 2017. Available from: www.safetyandquality.gov.au/our-work/ assessment-to-the-nsqhs-standards/nsqhsstandards-second-edition/. 
10. World Health Organization (WHO). Definition of key terms 2013. Geneva; WHO: 2013. Available from: www.who.int/hiv/pub/ guidelines/arv2013/intro/keyterms/en/.

11. Erhaze EK, Dowling M, Devane D. Parental presence at anaesthesia induction: A systematic review. Int I Nurs Pract 2016;22(4):397-407.

12. Fortier MA, Kain ZN. Treating perioperative anxiety and pain in children: A tailored and innovative approach. Pediatric Anesthesia 2015;25(1):27-35.

13. Manyande A, Cyna AM, Yip P, Chooi C, Middleton P. Non-pharmacological interventions for assisting the induction of anaesthesia in children. Cochrane Database Syst Rev. 2015;(7):CD006447.

14. Brioni JDV S, Ahmed R, Bein B. A clinical review of inhalation anesthesia with sevofurane: From early research to emerging topics. J Anesth 2017;31(5):764-778.

15. Rasti R, Jahanpour F, Motamed N. The effect of parental presence on anxiety during anesthesia induction in children 2 to 11 years of age undergoing surgery. Journal of Jahrom University of Medical Sciences 2014;12(1):9-17.

16. Lin CJ, Liu HP, Wang PY, Yu MH, Lu MC, Hsieh $L Y$ at al. The effectiveness of preoperative preparation for improving perioperative outcomes in children and caregivers. Behav Modif 2019;43(3):311-329.

17. Robinson $H$, Norton S. Jarrett $P$, Broadbent $E$. The effects of psychological interventions on wound healing: A systematic review of randomized trials. Br J Health Psychol 2017;22(4):805-835.

18. Anpuram L. A prospective study on effect of premedication with oral midazolam on preoperative anxiety in children with history of previous surgery. J Evid Based Med Healthc 2019;6(6):375-378.

19. Marechal C, Berthiller J, Tosetti S, Cogniat B, Desombres $\mathrm{H}$, Bouvet $\mathrm{L}$ et al. Children and parental anxiolysis in paediatric ambulatory surgery: a randomized controlled study comparing midazolam to tablet computer based interactive distraction. $\mathrm{Br}$ । Anaesth 2017;118(2):247-253.

20. Das S, Kumar A. Preoperative anxiety in pediatric age group - a brief communication. J Anesth Crit Care 2017;8(5):1-2.

21. Lerwick J. Minimizing pediatric healthcareinduced anxiety and trauma. World I Clin Pediatr 2016;5(2):143-150.

22. Gill FJ, Pascoe E, Monterosso L, Young J, Burr C, Tanner A et al. Parent and staff perceptions of family-centered care in two Australian children's hospitals. Eur J Person Centered Healthc 2014:1(2):317-325.
23. Yousef Y, Drudi S, Sant'Anna AM, Emil S. Parental presence at induction of anesthesia: Perceptions of a pediatric surgical department before and after program implementation. J Pediatr Surg 2018;53(8):1606-1610.

24. The Children's Hospital at Westmead. Policy no: O/C/06:8179-01:03. Anaesthesia: Parents attending the induction of - CHW. Policy and procedure. Sydney: The Children's Hospital at Westmead; 2014

25. Waseem $\mathrm{H}$, Mazzamurro RS, Fisher $\mathrm{AH}$ Bhowmik S, Zaman RA, Andrew A et al. Parental satisfaction with being present in the operating room during the induction of anesthesia prior to pediatric neurosurgical intervention: A qualitative analysis. J Neurosurg Pediatr 2018;21(5):528-534.

26. Stromgren M, Eriksson A, Bergman D, Dellve L. Social capital among healthcare professionals: A prospective study of its importance for job satisfaction, work engagement and engagement in clinical improvements. Int J Nurs Stud 2016;53:116125.

27. Belanger J, Kossick M. Methods of identifying and managing the difficult airway in the pediatric population. Am Assoc Nurse Anesth 2015;83(1):35-41.

28. Smith J. Parental presence during induction of Anaesthesia - An evidencebased practice review. Aust Nurs Midwif J 2017;24(10):1-2.

29. Aguilar Cordero MJ, Sánchez-López AM, Mur Villar N, García Garcia I, Rodríguez López MA, Ortegón Piñero A et al. Salivary cortisol as an indicator of physiological stress in children and adults; a systematic review. Nutricion Hospitalaria 2014;29(5):960-968.

30. Ozdogan HK, Cetinalp S, Kuran G, Tugal O, Tahiroglu M, Herdem UE Haytoglu S. The effects of maternal presence during anesthesia induction on salivary cortisol levels in children undergoing tonsillectomy and/or adenoidectomy. J Clin Anesth 2017:39:64-66.

31. Rasti-Emad-Abadi R, Naboureh A, Nasiri M, Motamed N, Jahanpour F. The effects of preanesthetic parental presence on preoperative anxiety of children and their parents: A randomized clinical trial study in Iran. Iran J Nurs Midwifery Res 2017;22(1):72-77

32. Sjöberg C, Amhliden H, Nygren JM, Arvidsson $\mathrm{S}$, Svedberg $\mathrm{P}$. The perspective of children on factors influencing their participation in perioperative care. J Clin Nurs 2015;24(1):2945-2953.

33. Boles J. Children's Corner: Perspectives on supportive care. Preparing children and families for procedures or surgery. Pediatric Nursing. 2016;42(3):147-9.

34. Al-Sagarat AY, Al-Oran HM, Obeidat $H$, Hamlan A, Moxham L. Preparing the family and children for surgery. Crit Care Nurs Quart 2017;40(2):99-107.
35. Chartrand J, Tourigny J, MacCormick J. The effect of an educational pre-operative DVD on parents' and children's outcomes after a same-day surgery: A randomized controlled trial. J Adv Nurs 2017;73(3):599-611.

36. Carlsson R, Henningsson RN. Visiting the operating theatre before surgery did not reduce the anxiety in children and their attendant parent. J Pediatr Nurs 2018;38:e24-e29.

37. Australian and New Zealand College of Anaesthetists (ANZCA). PS07 Guidelines on pre-anaesthesia consultation and patient preparation [Internet]. Melbourne; ANZCA: 2017 (cited 22 October 2019). Available from: www.anzca.edu.au/documents/ps04bpstatement-on-the-post-anaesthesia-careunit.pdf.

38. Racine NM, Riddell RP, Khan M, Calic M, Taddio A, Tablon P. Systematic review: Predisposing, precipitating, perpetuating, and present factors predicting anticipatory distress to painful medical procedures in children. J Pediatr Psychol 2016;41(2):159-181.

39. Kruger P, Rosen D. Parental presence at induction of anaesthesia is feasible with minimal preparation and resources. Can J Anaesth 2016;63(10):1207-1208.

40. Velzen J, Atkinson S, Rowley E, Martin JL. The tradition of anaesthetic rooms: Best practice or patient risk? Procedia Manufact 2015:3:59-66.

41. Hogan L, Harvey R. Creating a culture of safety by reducing noise levels in the OR. AORN J 2015;102(4):410.e1-410.e7.

42. Nightingale CE. NAP5-death knell for the anaesthetic room? Anaesthesia 2015;70(1):108-109.

43. Lopez-Perez B, Gummerum M, Wilson E, Dellaria G. Studying children's intrapersonal emotion regulation strategies from the process model of emotion regulation. Genet Psychol 2016;178(2):73-88.

44. Salamon A, Sumsio J, Harrison L. Infants draw on 'emotional capital' in early childhood education contexts: A new paradigm. Contemp Iss Early Childhood 2017;18(4):362-374

45. Bremner GJ, Slater AM, Johnson SP. Perception of object persistence: The origins of object permanence in infancy. Child Dev Perspect 2015;9(1):7-13.

46. Platt R, Williams SR, Ginsburg GS. Stressful life events and child anxiety: Examining parent and child mediators. Child Psychiatry Hum Dev 2016;47(1):23-34.

47. Hernik M, Broesch T. Infant gaze following depends on communicative signals: An eye-tracking study of 5-to 7-month-olds in Vanuatu. Dev Sci 2019;22(4):1-8.

48. Carey S, Zaitchik D, Bascandziev I. Theories of development: In dialog with Jean Piaget. Dev Rev 2015;38(36-54). 